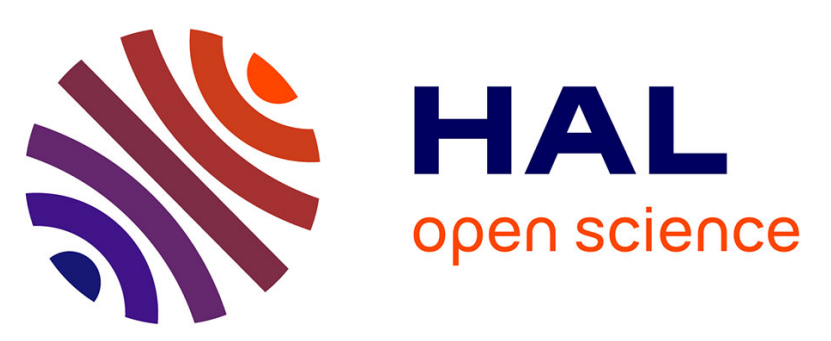

\title{
Ecological Footprint Model of Cultivated Land Based on Ecosystem Services in Beijing
}

Hui Guo, Di Wu, Lei Fa, Shunxiang Pei, Xuebing Xin, Shumin Ma, Sha Wu, Shiwei Dong

\section{To cite this version:}

Hui Guo, Di Wu, Lei Fa, Shunxiang Pei, Xuebing Xin, et al.. Ecological Footprint Model of Cultivated Land Based on Ecosystem Services in Beijing. 11th International Conference on Computer and Computing Technologies in Agriculture (CCTA), Aug 2017, Jilin, China. pp.159-169, 10.1007/978-3030-06137-1_17. hal-02124244

\section{HAL Id: hal-02124244 \\ https://hal.inria.fr/hal-02124244}

Submitted on 9 May 2019

HAL is a multi-disciplinary open access archive for the deposit and dissemination of scientific research documents, whether they are published or not. The documents may come from teaching and research institutions in France or abroad, or from public or private research centers.
L'archive ouverte pluridisciplinaire $\mathbf{H A L}$, est destinée au dépôt et à la diffusion de documents scientifiques de niveau recherche, publiés ou non, émanant des établissements d'enseignement et de recherche français ou étrangers, des laboratoires publics ou privés. 


\title{
Ecological Footprint Model of Cultivated Land Based on Ecosystem Services in Beijing
}

\author{
Hui Guo ${ }^{1}$, Di Wu${ }^{1}$, Lei Fa ${ }^{1}$, Shunxiang Pei ${ }^{1}$, Xuebing Xin ${ }^{1(\bowtie)}$,Shumin $\mathrm{Ma}^{1}$, Sha \\ $\mathrm{Wu}^{1}$, and Shiwei Dong ${ }^{2,3}$ \\ ${ }^{1}$ Forestry Experiment Center of North China, Chinese Academy of Forestry, Beijing \\ 102300, China \\ guohuistz@126.com,wudi1218edu@163.com, titafall@126.com, \\ psx0309@sina.com, xinxb01@163.com, liuma030425@163.com, \\ wusha@mail.iap.ac.cn \\ ${ }^{2}$ Beijing Research Center for Information Technology in Agriculture, Beijing Academy of \\ Agriculture and Forestry Sciences, Beijing 100097, China \\ ${ }^{3}$ National Engineering Research Center for Information Technology in Agriculture, Beijing \\ 100097, China \\ dshiwei2006@163.com
}

\begin{abstract}
The existing ecological footprint model is limited to the defects of material production and consumption. The researchers proposed an ecological footprint model based on ecosystem services (EF-ES) to strengthen research into the services provided by ecosystems, and calculated and analyzed the cultivated land in Beijing from 1995 to 2010. The results shows that: (1) from 1995 to 2000, the equilibrium factors of cultivated land in Beijing were relatively stable in EF-ES, but the yield factors in 2000 were significantly lower than that of the other years; (2) the equilibrium factors based on EF-ES were far less than other methods results. It was mainly due to ecosystem services provided by farmland ecosystem which is far less than the other ecosystem types. The yield factor based on EF-ES was similar to the result of EF-NPP; (3) the annual ecological carrying capacity was the lowest, and the ecological deficit was the highest in 2000. The ecological deficit gradually decreased from 1995 to 2010. Compared with EF-NPP, the ecological deficit of EF-ES was small, which showed that the ecological services provided by cultivated land can compensate for the ecological deficit caused by material production. The calculation results based on the model accord with the development of urban agriculture in Beijing. So EF-ES has an objective and comprehensive response to the ecological security of cultivated land, and it is a good expression for the localization of ecological footprint.
\end{abstract}

Keywords: ecosystem service · ecological footprint · equivalence factor · yield factor · cultivated land.

\section{Introduction}

In 1990, the ecological footprint method was introduced into China. The model attracted a large number of scholars to evaluate the ecosystem based on land supply 
and demand in different areas. These scholars further enriched and improved the theoretical system of ecological footprint model on the original basis [1]. Ecological footprint -life cycle assessment (EF-LCA) [2], ecological footprint -input output analytical model (EF-IOA) [3,4], ecological footprint-energy (EF-E) [5,6], ecological footprint-three dimensional (EF-3D) [7-10], ecological footprint-times series (EF-TS) [11], and ecological footprint-net primary productivity (EF-NPP) [12,13] enhanced the performance of ecological footprint as an indicator of eco-system evaluation. Some scholars had introduced the theory of ecological footprint into individual land types. Cultivated land had been widely regarded as the foundation of human life. It was important to study the ecological carrying ability of cultivated land. Now, the present cultivated land ecological footprint model had several problems: (1) Equivalence factor and production coefficient were generally used in the world average, so they didn't reflect the local ecological footprint. (2) These parameter mainly considered the physical supply and consumption of the ecosystem, and there was less consideration for the provision of the ecosystem and support services. (3) EFNPP represented the biological productivity of the land, but its ability that studied ecosystem services was relatively deficient. In view of these problems, the paper put forward the ecological.

\section{Study Area}

Beijing lied northwest of the north China plain $\left(39.4^{\circ} \mathrm{N}-41.6^{\circ} \mathrm{N}, 115.7^{\circ} \mathrm{E}-117.4^{\circ} \mathrm{E}\right)$. It covered an area of $16,411 \mathrm{~km}^{2}$. The northeast of Beijing was high, and the southeast was low, and the geomorphological type was diverse in Figure1. Beijing located in the warm temperate zone, and it had sub-humid continental monsoon climate. The northern and western mountains of Beijing were ecological conservation areas, and the southeastern plain was the main area of urban construction and agricultural development. According to the 2th national land survey data of Beijing, the total area of cultivated land was $227,170.43 \mathrm{hm}^{2}$. It accounted for $13.8 \%$ of the total area of the city. Different from the agricultural production area, agricultural area in Beijing had social service function, ecological service function, landscape culture and leisure tourism function except the production function [14]. So it was necessary to study the ecosystem services of cultivated land.

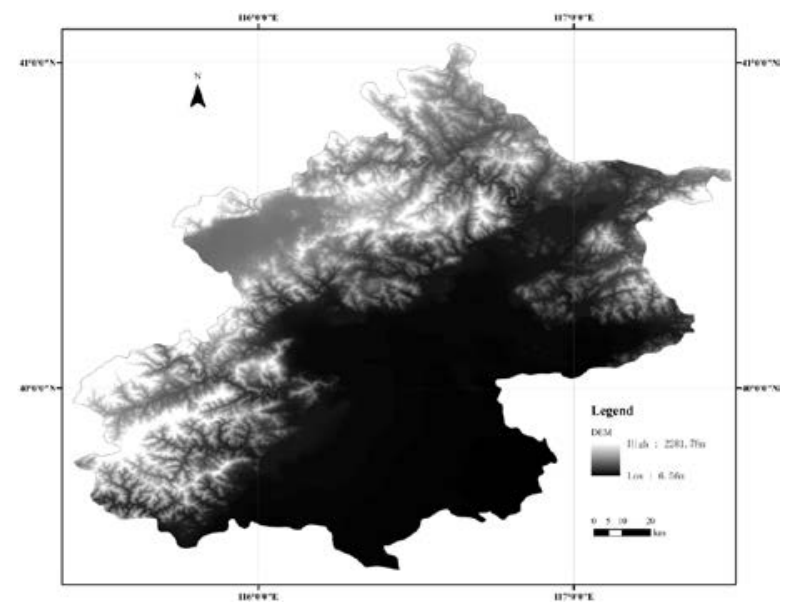

Fig. 1. Location of the study are 


\section{Material and Methods}

\subsection{Material}

The data in this study derived from <Compilation of national cost and income of agricultural products> and <Beijing statistical yearbook> in 1996, 2001, 2006 and 2011. The <Compilation of national cost and income of agricultural products $>$ was lack of wheat, corn and rice data in Beijing in 2011. So the missing data came from the 2010 NDCR's minimum purchase price or the Beijing purchase price. The amount of material consumed in wheat, corn and rice was used in the 2010 national average. The land cover data set was provided by Data Center for Resources and Environmental Sciences, Chinese Academy of Sciences (RESDC) (http://www.resdc.cn) in 1995, 2000, 2005 and 2010 in Figure 2.
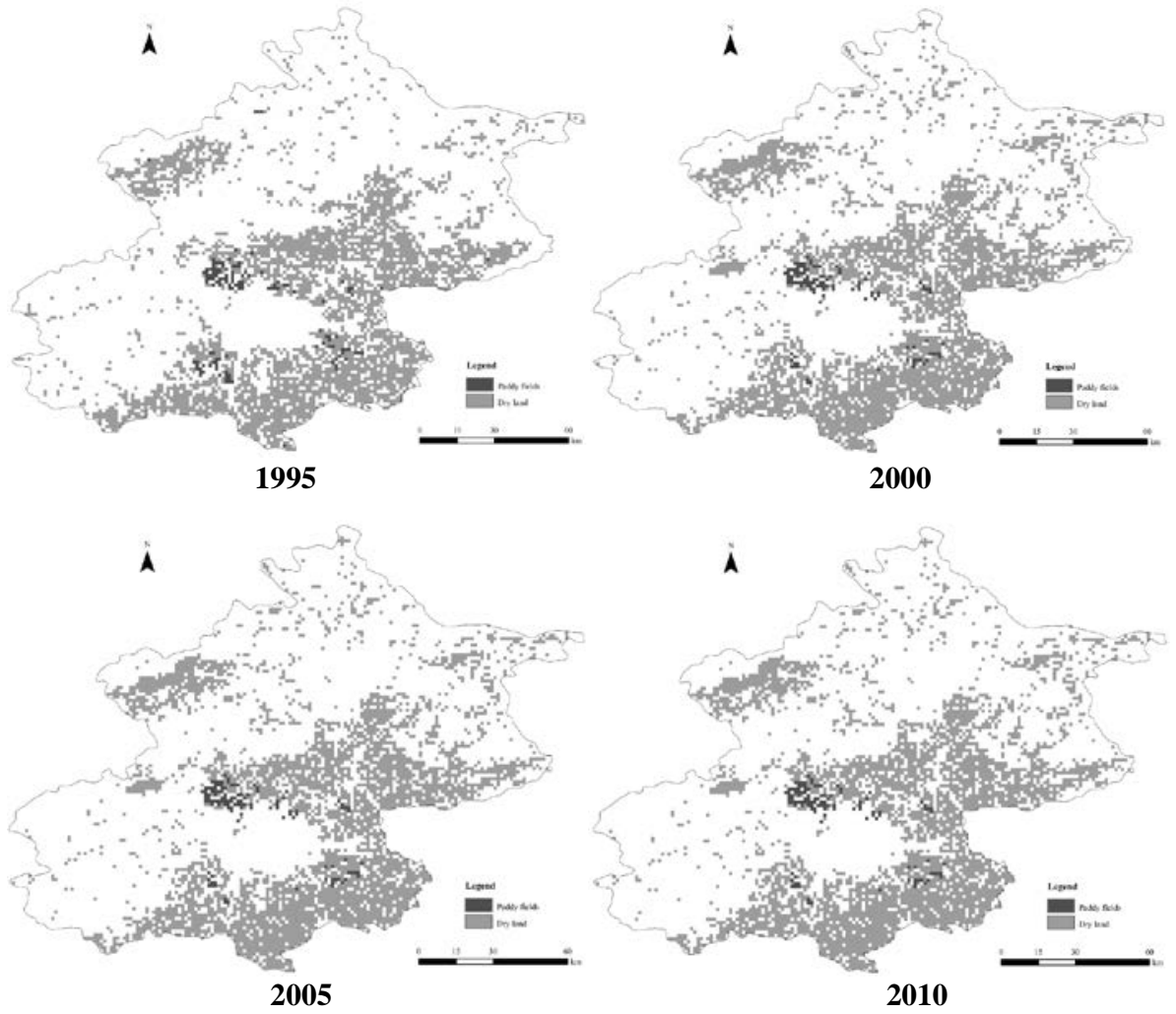

Fig. 2. Cultivated land distribution in Beijing 


\subsection{Method}

Following the approach development by Wackernagel et al. [15], we calculated EFES by summarizing the footprints of cultivated land. Equivalence factor and yield factor were key parameters in ecological footprint model. Most studies used global common factors or factors which obtained from material production. It was difficult to reflect the ecological service carrying capacity in local areas. The paper built EF-ES model to study the cultivated land in Beijing by local equivalence factor and yield factor. Evaluation method was used to calculate the value of ecosystem services [16]. In the study, ecosystem services included 11 types of services in Figure 3.

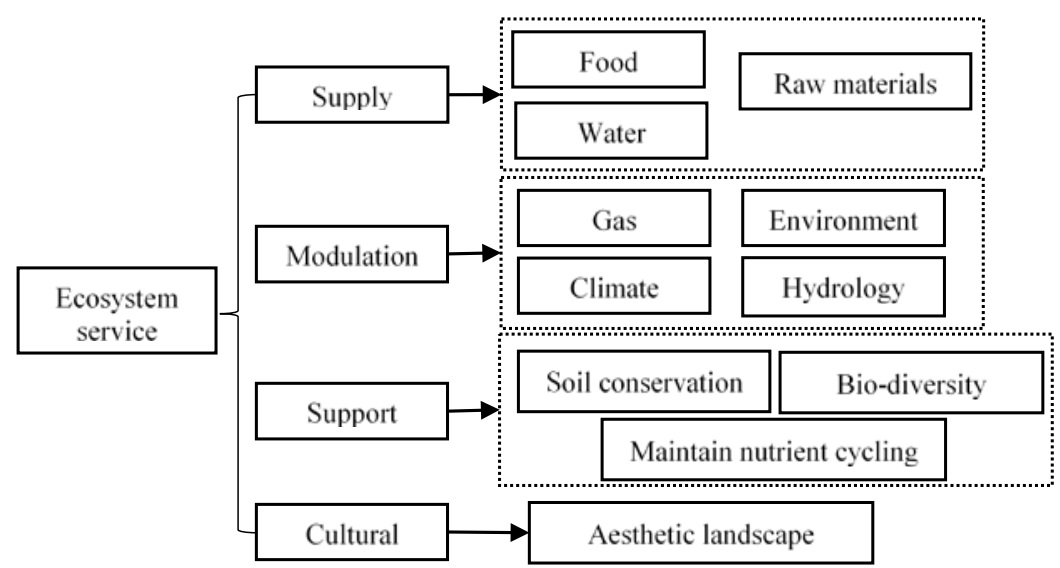

Fig.3. Cultivated land function

Equivalence Factor. Equivalence factor $\left(\boldsymbol{r}_{\boldsymbol{j}}\right)$ is used to convert the ecosystem services of different lands into the land area with the same ecosystem services. It is calculated as follows:

$$
r_{j}=\frac{P_{j}}{\overline{P_{N P}}}
$$

Where $P_{j}$ is ecosystem services value of ecosystem type $\mathrm{j}$ (Yuan); $\overline{P_{N P}}$ is the average ecosystem services value of all types of land use (Yuan).

Yield Factor. Yield factor is used to convert the land area of an ecosystem in a given area into a corresponding whole area. It is used to contrast between different regions. It is calculated as follows:

$$
y_{j}=\frac{E_{j}}{\bar{E}_{J}}
$$


Where $E_{j}$ is the per unit area ecosystem services value of national/provincial ecosystem land $\mathrm{j}$; $\bar{E}_{j}$ is the corresponding to the above per unit area ecosystem services value of global / national ecosystem land $\mathrm{j}$;

EF-ES Model. Ecological carrying capacity (ECC) means that certain areas can provided the total area of human ecological services. It was calculated as:

$$
E C C=a_{j} \times r_{j} \times y_{j}
$$

Where $a_{j}$ is the area of bioproductive land j; Ecological footprint ( $E F$ ) means that certain areas can consume the total area of human ecological services. It is calculated as:

$$
E F=a_{j} \times r_{j}
$$

Ecological deficit $(E D)$ is used to directly reveal whether or not the consumption of natural capital exceeds the bio-capacity $(E C C)$ in the region. Ecological deficit $(E D)$ is calculated as the following:

$$
E D=E F-E C C
$$

Positive ecological deficit values indicate an "over-consumption” or unsustainable situation, whereas negative values show a sustainable situation due to ecological surplus in the region of interest.

\section{Results}

\subsection{Cultivated Land Ecosystem Service Value}

First of all, the ecosystem services value of China's cultivated land was calculated in 1995, 2000, 2005 and 2010 by equivalent factor method (Table 1). Secondly, the ecosystem services value of Beijing's cultivated land was calculated in 1995, 2000, 2005 and 2010 by equivalent factor method (Table 1).

Table 1. Ecosystem services value of cultivated land in China and Beijing from 1995 to 2010 $\left(\right.$ Yuan $\left./ \mathrm{km}^{2}\right)$

\begin{tabular}{lcccc}
\hline & 1995 & 2000 & 2005 & 2010 \\
\hline Cultivated land in China & $2,214,661.62$ & $1,139,254.92$ & $1,988,219.61$ & $3,464,850.70$ \\
Dryland in China & $2,302,566.61$ & $1,183,550.98$ & $2,064,450.79$ & $3,597,698.02$ \\
Paddy fields in China & $1,975,269.11$ & $1,015,315.55$ & $1,771,000.17$ & $3,086,304.54$ \\
Cultivated land in Beijing & $1,535,905.86$ & $472,094.56$ & $1,582,140.54$ & $2,454,413.92$ \\
Dryland in Beijing & $1,544,385.96$ & $474,173.17$ & $1,611,423.16$ & $2,499,840.78$ \\
Paddy fields in Beijing & $1,324,859.77$ & $406,771.99$ & $1,382,367.99$ & $2,144,501.82$ \\
\hline
\end{tabular}


As show in Table 1, the ecosystem service value of cultivated land in Beijing was much less than that in China. It showed that the ecosystem services provided by cultivated land in Beijing were much lower than the average level of cultivated land in China. The value of ecosystem service provided by dry land was larger than that provided by paddy fields. The value of ecosystem services provided by cultivated land in 2000 was much lower than in the other three years. The value of ecosystem services provided by cultivated land in 2010 was much higher than that in the other three years.

\subsection{Equivalence Factor of Cultivated in Beijing}

According to the formula (1), the equilibrium factors of cultivated land in Beijing were calculated in 1995, 2000, 2005 and 2010. The results were shown in Table 2. From 1995 to 2005, the equilibrium factor rose from 0.229 to 0.256 . It dropped to 0.252 in 2010. There were a few paddy fields in Beijing, and most of them were dry land. The equilibrium factors of paddy field and dry land were consistent with the overall equilibrium factors of cultivated land. The equilibrium factors of paddy field was slightly lower than that of dry land. Because paddy fields need to consume a lot of water resources relative to dry land.

Table 2. Equivalence factor of cultivated in Beijing from 1995 to 2000

\begin{tabular}{lllll}
\hline & 1995 & 2000 & 2005 & 2010 \\
\hline Equivalence factor of dry land & 0.229 & 0.243 & 0.260 & 0.256 \\
Equivalence factor of paddy fields & 0.197 & 0.208 & 0.223 & 0.220 \\
Equivalence factor of dry land & 0.229 & 0.242 & 0.256 & 0.252 \\
\hline
\end{tabular}

The equilibrium factors of ecosystem services were compared with other research methods of cultivated land factors (Table 3). The global cultivated land equilibrium factors was about 3.00. Jianxing L. calculated the factor of cultivated land in China was higher than the other methods, which was 5.25. But the cultivated land equilibrium factor of EF-NPP decreased significantly, and it was 1.74. Compared to other research methods, the method of calculating the value of ecosystem services was greatly reduced. Consequently, the ecological footprint model based on material production and consumption has higher equilibrium factor. But ecosystem services provided by cultivated land were much lower than the other land types. So its equilibrium factors was much lower than the other methods.

Table 3. Equivalence factors calculated in various studies for ecological footprint

\begin{tabular}{ccccccc}
\hline & $\begin{array}{l}\text { Refer. } \\
{[17]}\end{array}$ & $\begin{array}{l}\text { Refer. } \\
{[18]}\end{array}$ & $\begin{array}{l}\text { Refer. } \\
{[19]}\end{array}$ & $\begin{array}{l}\text { Refer. } \\
{[20]}\end{array}$ & $\begin{array}{l}\text { Refer. } \\
{[21]}\end{array}$ & $\begin{array}{l}\text { Refer. } \\
{[21]}\end{array}$ \\
\hline Equilibrium factor & 2.8 & 3.16 & 2.83 & 5.25 & 1.74 & 1.03 \\
\hline
\end{tabular}

\subsection{Yield Factor of Cultivated in Beijing}

According to the formula (2), the yield factors of cultivated land in Beijing were calculated in 1995, 2000, 2005 and 2010 (Table 4). The yield factors in Beijing were 
relatively stable in 1995, 2005 and 2010. But it was very low in 2000. Because the dry land and paddy field had the same standard equivalent factor, so they had the same yield factors which was not studied. Among them, the minimum yield factor was 0.41 in 2000; and the highest factor was 0.79 in 2005.

Table 4. Yield factor of cultivated in Beijing from 1995 to 2000

\begin{tabular}{lllll}
\hline & 1995 & 2000 & 2005 & 2010 \\
\hline Yield factor & 0.69 & 0.41 & 0.79 & 0.71 \\
\hline
\end{tabular}

The yield factors of ecosystem services were compared with other research methods of cultivated land factors (Table 5). The yield factors of cultivated land was the highest in China based on EF-NPP, which was 1.74; but the yield factors was 0.83 in Beijing, and it was $47.70 \%$ of China's cultivated land yield factors. As a large city, agriculture was not the main industry in Beijing, and its yield factor was lower than the other areas in China. Other methods of calculation were closer to the cultivated factor. In 2000, the yield factors of cultivated land in Beijing was only 0.41, which was far smaller than that calculated by other methods. But the yield factor of cultivated land in Beijing based on ecosystem services was close to the yield factor calculated by EF-NPP in the other years.

Table 5. Yield factors calculated in various studies for ecological footprint

\begin{tabular}{cccccc}
\hline & Refer. [17] & Refer. [22] & Refer. [20] & Refer. [1] & Refer.[1] \\
\hline Yield factor & 1.66 & 1.71 & 1.65 & 1.74 & 0.83 \\
\hline
\end{tabular}

\subsection{EF-ES Model in Beijing}

According to formula (3), (4) and (5), EF-ES of cultivated land in Beijing were studied, and the results were shown in Table 6. The per capita ecological carrying capacity of cultivated land was highest in 2005, and the ecological carrying capacity per capita was the lowest in 2000. The per capita ecological footprint was the highest in 2000 , and the per capita ecological footprint was the lowest in 2010 . The per capita ecological deficit was the highest in 2000, and the per capita ecological deficit was the lowest in 2010.

Table 6. EF-ES of cultivated land in Beijing from 1995 to 2010 (nhm²/ten thousand people)

\begin{tabular}{lllll}
\hline & 1995 & 2000 & 2005 & 2010 \\
\hline Per capita ecological carrying capacity & 43.48 & 27.27 & 50.92 & 30.92 \\
Per capita ecological footprint & 63.02 & 66.51 & 64.45 & 43.55 \\
Per capita ecological deficit & 19.54 & 39.24 & 13.53 & 12.63 \\
\hline
\end{tabular}

\subsection{EF-ES Compared Its Results with EF-NPP}

EF-NPP model was used to calculate ecological footprint and ecological carrying of cultivated land in Beijing (equilibrium factor and yield factor are obtained by 
Moucheng L. [1, 21]), and the results were shown in Table 7. Ecological carrying capacity and ecological footprint which calculated by EF-NPP were significantly larger than those which calculated by EF-ES, but the ecological deficit was slightly larger than the EF-ES calculation results.

Table 7. EF-NPP (nhm²/ ten thousand people)

\begin{tabular}{ll}
\hline & EF-NPP(2001) \\
\hline Per capita ecological carrying capacity & 234.94 \\
Per capita ecological footprint & 283.06 \\
Per capita ecological deficit & 48.12 \\
\hline
\end{tabular}

\section{Discussion}

\subsection{Equivalence Factor}

Equivalence factor of cultivated land based on EF-ES was the least compared with other calculation methods. The main reasons were as follows: most methods were calculated on the basis of material yield. Cultivated land had maximum material yield compared with other ecosystem types. So cultivated land had the maximum equivalence factor by the other method. But the equivalence factor of EF-ES was based on the ability of different ecosystems to provided services. Cultivated land provided more supply services but it provided less modulation, support, and cultural services than the other types of ecosystem. So the equivalence factor was minimum by EF-ES. But in the study of the ecological capacity of the metropolis, the research on the provision of services for various types of land was more realistic than the research of simple matter. Therefore, the paper argued that the method of ecosystem service based on ecological factor extraction could better reflect the carrying capacity of ecosystem.

\subsection{Yield Factor}

The yield factor transformed the local types of land area into a corresponding whole area. Its main purpose was to facilitate the comparison of land ecological carrying capacity in different regions. Therefore, the calculation of this factor is mainly aimed at the land productivity. So yield factor based on EF-ES is similar to the result of the yield factor based on EF-NPP. The quality and ecological potential of cultivated land in Beijing were at a low level in China [23]. From 1995 to 2010, the yield factors of cultivated land were the lowest in 2000 in Beijing. Drought occurred throughout the country this year, and it resulted in serious reduction in grain production and poor productivity of cultivated land. So the yield factor based on EF-ES was in line with natural and socio-economic development.

\subsection{Local Ecological Footprint Model in Beijing}

The ecological footprint model was not standardized accounting standard system. It had different emphases, and different researchers studied the ecological footprint of the same area with different parameters and productivity standard. So it had 
shortcoming in the completeness of accounting, the comparability and reliability of accounting results. This had weakened the ability of the ecological footprint model as an ecosystem assessment tool. EF-ES was constructed in this study in Beijing. The model departed from the limitations of prior material production, and it discussed the ecological carrying capacity from the perspective of ecosystem services. Ecological carrying capacity and ecological footprint which calculated by EF-ES were much lower than other methods. But its ecological deficit was slightly less than EF-NPP's results. This was due to that EF-ES considered the supply of ecosystem services except the production and consumption. It could make up for the independent material production. As a result, the ecological deficit had been reduced by the model. The method reflected the ability of ecosystem services which provided by a certain ecosystem, and conformed to the judgment requirements of the contradiction between supply and demand of ecosystem services in the current society. Wenjun, J. et al.[24] constructed an ecological footprint model based on ecosystem services, and the model was used to evaluate the impact of water pollutant emissions. Its model had good pertinence, but it was not universal. EF-ES in this article could be applied to all ecosystems.

From 1995 to 2010, there was no drastic change in the area and the layout of cultivated land (Fig.2). Therefore, the change of ecological footprint of cultivated land should be caused by other reasons. The use of machinery is less and less, and electricity has become the main mode of energy of consumption (Table 8). It showed that the construction of ecological and social functions of urban agriculture in Beijing has achieved remarkable results. The ecological deficit in Beijing had improved from 1995 to 2010. The results were consistent with the development of urban agriculture in Beijing.

The study also had some shortcoming: because the ecological footprint model based on ecosystem services was constructed for cultivated land in this paper, and the data of other ecosystems were not enough to form a holistic judgment; the selection of ecosystem services types was still limitations; the data in some cities were incomplete in <Compilation of national cost and income of agricultural products $>$. Therefore, obtaining fully unified the basic data was difficult.

Table 8. Agricultural production condition in Beijing

\begin{tabular}{cccc}
\hline & $\begin{array}{c}\text { Powers of agriculture machine } \\
\mathrm{kW} / \mathrm{hm}^{2}\end{array}$ & $\begin{array}{c}\text { Electricity consumption } \\
\mathrm{kW} \cdot \mathrm{h} / \mathrm{hm}^{2}\end{array}$ & $\begin{array}{c}\text { Fertilizer consumption } \\
\mathrm{t} / \mathrm{hm}^{2}\end{array}$ \\
\hline 1995 & 13.60 & $5,859.16$ & 0.55 \\
2000 & 10.71 & $15,346.12$ & 0.48 \\
2005 & 8.72 & $10,890.50$ & 0.38 \\
2010 & 8.14 & $13,094.54$ & 0.40 \\
\hline
\end{tabular}

\section{Conclusions}

This study constructed EF-ES model, and studied cultivated land in Beijing. The ecosystem services value of cultivated land per unit area in Beijing was less than that of the whole country. In 2000, the ecosystem services value of cultivated land per unit area was the smallest in 4 years. The equilibrium factor of cultivated land obtained by 
10

EF-ES was the smallest compared with other methods. The yield factor of cultivated land obtained by EF-ES was equivalent to the yield factor calculated by EF-NPP model. According to the EF-ES model results, the per capita ecological deficit was higher in 2000 because of drought. Ecological deficit was declining from 1995 to 2010 except 2000. It showed that the ecological pressure of cultivated land in Beijing had been alleviated. The calculation results of EF-ES accorded with the development of agricultural in Beijing. The model could better realize the localization of ecological footprint, and reflect the change of ecosystem services in a certain ecosystem.

\section{Acknowledgments}

This study is supported by the National Key Technology Research and Development Program (No. 2015BAD07B0202) and the Youth Foundation of Forestry Experiment Center of North China (No. ECFNC2014-03).

\section{References}

1. Chengmou,L., Wenhua,L., Gaodi,X.: Estination of China Ecological Footprint Production Coefficient Based on Net Primary Productivity. Chin. J. Ecol. 29(3), 592-597 (2010)

2. De Alvareng, R. A. F., Da Silva Júnior, V. P., Soares, S. R. : Comparison of the Ecological Footprint and a Life Cycle Impact Assessment Method for a Case Study on Brazilian Broiler Feed Production. J. Clea. Prod. 28, 25-32 (2012)

3. Bicknell, K. B., Ball, R. J., Cullen, R., Bigsby, R.H.: New Methodology for the Ecological Footprint with an Application to the New Zealand Economy. Ecol. Econ. 27(2), 149-160 (1998)

4. Kratena, K.: From Ecological Footprint to Ecological Rent: An Economic Indicator for Resource Constraints. Ecol. Econ. 64(3), 507-516 (2008)

5. Zhao, S., Li, Z. Z., Li, W .D. : A Modified Method of Ecological Footprint Calculation and Its Application. Ecol. Mode. 185(1), 65-75 (2005)

6. Pereira, L., Ortega, E.: A Modified Footprint Method: The Case Study of Brazil. Ecol. Indi. 16, 113-127 (2012)

7. Niccolucci, V., Bastianoni, S., Tiezzi, E. B. P., Wackernagel, M., Marchettini, N.: How Deep is the Footprint? A 3D Representation. Ecol. Mode. 220(20), 2819-2823 (2009)

8. Niccolucci, V.,Galli, A,,Reed, A.,Reed, A., Neri, E., Wackemagel, M., Bastianoni, S.: Towards a 3D National Ecological Footprint Geography. Ecol. Mode. 222(16), 2939-2944 (2011)

9. Fang, K. : Ecological Footprint Depth and Size: New Indicators for a 3D Model. Acta Ecol. Sin. 33(1): 267-274 (2013)

10. Fang, K. : Assessing the Natural Capital Use of Eleven Nations: An Application of a Revised Three-dimensional Model of Ecological Footprint. Act. Ecol. Sin.35(11), 37663777 (2015)

11.WWF, ZSL, GFN.:Living Planet Report 2012[R] (2013)

12. Venetoulis, J., Talberth, J.: Refining the Ecological Footprint. Envi. Deve. Sust. 10(4), 441-469 (2008)

13. Gao,M., Zhiyuan, R., Hongzhu, H.: Ecological Footprint Calculation of Shaanxi Province Based on Net Primary Productivity. J. Shaa. Nor. Univ.(Natu. Scie. Edit.) 42(5): 84-89. (2014)

14.Zhijun, S., Liming, L.: Spatial Characteristics Analysis for Multifunctional Transition of Suburban Agricultural Areas in Beijing. Scie. Geog. Sin.4. 427-433 (2011) 
15. Wackernagel, M., Monfreda, C., Moran, D., Wermer, P., Goldfingerm, S., Deumling, D., Murray, M. : National Foorprint and Biocapacity Accounts 2005. The underlying calculation method. Global Footprint Network, Oakland.www.footprintnetwork.org. (2005)

16. Gaodi,X.,Caixia, Z.,Leiming, Z.,Wenhui, C.,Shimei, L.:Improvement of the Evaluation Method for Ecosystem Service Value Based on Per Unit Area. J. Natu. Reso. 30(8), 12431254 (2015)

17. Wackernagel, M., Reese, E.: Our Ecological Footprint: Reducing Human Impact on the Earth. New Society Publishers. 192-210 (1996)

18. World wildlife fund: Living Planet Report 2000. http://www.panda.org /downloads/general/lpr_2000.pfd.

19. Chambers, N., Smmons, C., Wackernagel, M.: Ecological Footprint Analysis Towards a Sustainability Indicator for Business, pp. 154 - 158. London Earthscan Publications Ltd (2001)

20. Jianxing, L.: Time Series and Geographical Distribution of Ecological Footprint for China. Shenyang: Northeastern University (2004)

21. Chengmou,L., Wenhua,L.: Calculation of Equivalence Factor Used in Ecological Footprint for China and Its Provinces Based on Net Primary Production. J. Ecol. Rur. Envi. 26(5), 401-406 (2010)

22. Gaodi, X., Chunxia,L., Shengkui, C., Du, Z.: Evaluation of Natural Capital Utilization with Ecological Footprint in China. Reso. Scie. 23(6), 20-23 (2001)

23.Xiumei, T., Yuchun, P., Xingyao,H., Yu,L.: Calculation Method of Cultivated Land Consolidation Ecological Potential in China. J. Agr. Eng. Res. 31(17): 270-277 (2015)

24. Wenjun, J., Qingwen, M., Wenhua, L., Anthony, F.: Development and Application of Ecosystem-Service-Based Ecological Footprint Models. Reso. Scie. 36(11): 2392-2400 (2014) 